
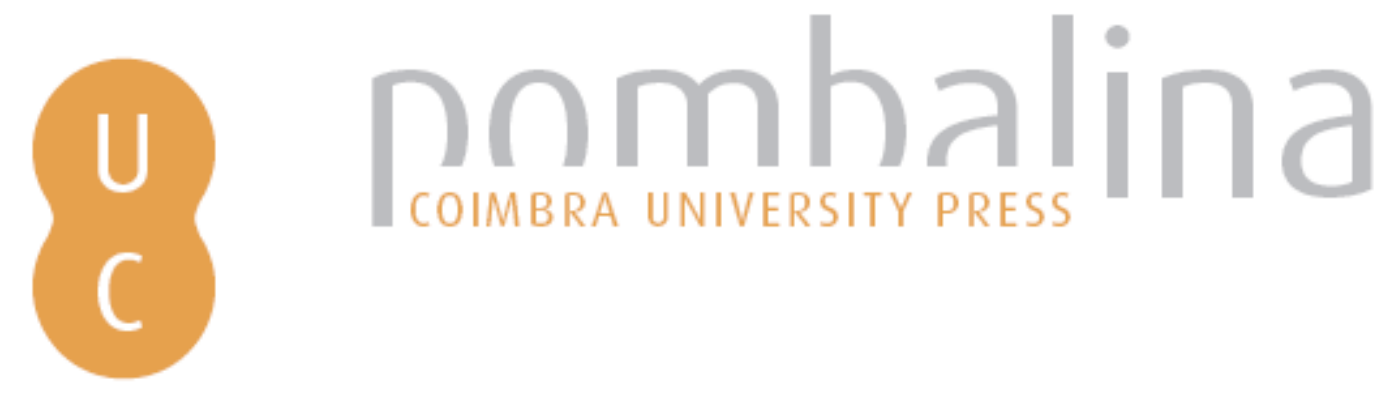

\title{
Os consumos alimentares de um hospital quinhentista: o caso do Hospital das Caldas em vida de Rainha D. Leonor
}
Autor(es):
Rodrigues, Lisbeth de Oliveira
Publicado por: Imprensa da Universidade de Coimbra
URL
persistente:
URI:http://hdl.handle.net/10316.2/31579
DOI:
DOI:http://dx.doi.org/10.14195/978-989-26-0201-1_2
Accessed : $\quad$ 26-Apr-2023 12:47:33

A navegação consulta e descarregamento dos títulos inseridos nas Bibliotecas Digitais UC Digitalis, UC Pombalina e UC Impactum, pressupõem a aceitação plena e sem reservas dos Termos e Condições de Uso destas Bibliotecas Digitais, disponíveis em https://digitalis.uc.pt/pt-pt/termos.

Conforme exposto nos referidos Termos e Condições de Uso, o descarregamento de títulos de acesso restrito requer uma licença válida de autorização devendo o utilizador aceder ao(s) documento(s) a partir de um endereço de IP da instituição detentora da supramencionada licença.

Ao utilizador é apenas permitido o descarregamento para uso pessoal, pelo que o emprego do(s) título(s) descarregado(s) para outro fim, designadamente comercial, carece de autorização do respetivo autor ou editor da obra.

Na medida em que todas as obras da UC Digitalis se encontram protegidas pelo Código do Direito de Autor e Direitos Conexos e demais legislação aplicável, toda a cópia, parcial ou total, deste documento, nos casos em que é legalmente admitida, deverá conter ou fazer-se acompanhar por este aviso.

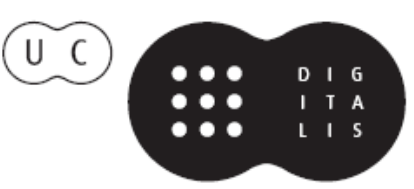


Isabel dos Guimarães Sá Máximo García Fernández (directores)

\section{PORTAS ADENTRO comer, vestir, habitar} (ss. XVI-XIX) 


\title{
OS CONSUMOS ALIMENTARES DE UM HOSPITAL QUINHENTISTA: O CASO DO HOSPITAL DAS CALDAS EM VIDA DE RAINHA D. LEONOR
}

\author{
LiSBETH DE OLIVEIRA RODRIGUES \\ Bolseira de doutoramento da FCT no Departamento de História ${ }^{1}$ \\ Universidade do Minho
}

\begin{abstract}
A história dos hospitais modernos tem sido alvo de um crescente número de estudos de âmbito nacional e internacional desde os inícios do século XX. Quase todos mencionam a reforma dos hospitais ao longo do século XVI, à qual os países protestantes não ficaram imunes, inscrevendo-a no conjunto das mudanças que assinalam a transição entre a Idade Média e o Período Moderno europeu. Regra geral, a historiografia actual admite que os hospitais medievais constituíam simultaneamente locais de abrigo para peregrinos e pobres doentes, sem qualquer tipo de separação ou especialização de edifícios, espaços e funções². Esta ambiguidade começou a desaparecer quando, nos finais do século $\mathrm{XV}$, os estados modernos procuraram, através da reforma hospitalar, distinguir entre hospitalidade e cura de enfermos ${ }^{3}$; foram criadas unidades hospitalares a partir da

${ }^{1}$ Trabalho elaborado no âmbito do projecto Portas Adentro: modos de habitar do século XVI a XVIII em Portugal, financiado pela FCT (PTDC/HAH/71309/2006).

${ }^{2}$ Ver Katharine Park, «Medicine and Society in Medieval Europe, 500-1500», in Andrew Wear (ed.), Medicine in Society, Cambridge, Cambridge University Press, 1992, pp. 75-90; Lindsay Granshaw, «The Hospital», in Wayne J. Urban (ed.), Gender, Race and National Education Association: Professionalism and its Limitations, New York, Routledge, 2000, pp. 1181-1183.

3 Ver Katharine Park e John Henderson, «The First Hospital Among Christians: The Ospedale di Santa Maria Nuova in Early Sixteenth Century Florence», Medical History, vol. 35, 1991, p. 170; Daniel Hickey, «Closing Down Local Hospitals in Seventeenth-Century France: The Mount Carmel and St. Lazare Reform Movement». Histoire Sociale - Social History, vol. XXV, 1992, n. 49, pp. 9-33.
\end{abstract}


incorporação de pequenos hospitais medievais, dando origem ao hospital geral, em que a medicina assumia um papel fundamental. No entanto, muita desta historiografia baseia-se numa abordagem de «cima para baixo», procurando descortinar as motivações religiosas dos membros da Casa Real na sua formação, ou a resposta institucional dada ao crescente número de pobres nos meios urbanos ${ }^{4}$.

No caso português, situa-se geralmente o início da reorganização da assistência hospitalar no ano de 1479, no qual o futuro rei D. João II obteve uma autorização papal para estabelecer o Hospital Real de Todos os Santos em Lisboa, o primeiro hospital geral, criado para substituir as dispersas e decadentes instituições assistenciais criadas por legados pios tardo-medievais. Tal como vinha acontecendo em outros países da Europa, muitos hospitais portugueses foram reformados ou criados de raiz nos finais do século XV e durante o século XVI como resultado do reforço do poder da Coroa ${ }^{5}$. Para além do Real Hospital de Lisboa, outros hospitais foram peças-chave na reconfiguração do espaço urbano, representando as novas atitudes cívicas que tinham como objectivo reforçar a coesão social e legitimar a autoridade do rei, assumindo um papel importante na política régia da assistência ${ }^{6}$. No entanto, estas alterações não foram abruptas,

${ }^{4}$ Destacam-se os trabalhos dos historiadores franceses, como Léon Lallemand, Histoire de la Charité: Les Temps Modernes du XVI au XIX siècle, Paris, Alphonense Picard et Fils, 1910-12; Christian Paultre, De la répression de la mendicité et du vagabondage en France sous l'ancien régime, Paris, Recueil Sirey, 1906; Jean Pierre Gutton, La Société et les pauvres en Europe (XVeXVIIe siècles), Paris, PUF, 1974; Jean Imbert, Le Droit Hospitalier de L'Ancien Régime, Paris, PUF, 1993; entre outros que abordam os hospitais do período moderno enfatizando a acção da Coroa. Ver ainda Charles H. Parker, The Reformation of Community. Social Welfare and Calvinist Charity in Holland, 1572-1620, Cambridge, Cambridge University Press, 1998; Tim McHugh, Hospital Politics in Seventeenth Century France. The Crown, Urban Elites and the Poor, Aldershot, Ashgate, 2007; Carol K. Manzione, Christ's Hospital of London 1552-1598. A Passing Deed of Piety, Selinsgrove, Susquehanna University Press, 1995. Outros trabalhos, mais recentes, abrem novas perspectivas sobre o estudo dos hospitais. Ver John Henderson, The Renaissance Hospital. Healing the Body and Healing the Soul, New Haven and London, Yale University Press, 2006; Sandra Cavallo e David Gentilcore (eds.), Spaces, Objects and Identities in Early Modern Italian Medicine, London, Blackwell, 2008. Estas duas obras rompem com a tradição anterior e centram-se na análise das instituições hospitalares sob o ponto de vista da cultura material, dos espaços e das dinâmicas internas.

${ }^{5}$ Maria de Lurdes Pereira Rosa, As Almas Herdeiras. Fundação de Capelas Fúnebres e Afirmação da Alma como Sujeito de Direito (Portugal, 1400-1521), tese de doutoramento, LisboaParis, FCSH, UNL-EHESS, 2005, pp. 151-201; José Pedro Paiva (coord.), Portugaliae Monumenta Misericordiarum, vol. III, Lisboa, União das Misericórdias-CEHR, 2004, pp. 107118; António Domingues de Sousa Costa, «Hospitais e Albergarias na Documentação Pontifícia da Segunda Metade do Século XV», Sep. de A Pobreza e a Assistência aos Pobres na Península Ibérica Durante a Idade Média, Actas das Primeiras Jornadas Luso-Espanholas de História Medieval, Lisboa, 25-30 de Setembro de 1972, Imprensa Nacional - Casa da Moeda, 1973, pp. 259-327.

${ }^{6}$ Ver Maria de Lurdes Pereira Rosa, ob. cit.; Isabel dos Guimarães Sá, «Os Hospitais Portugueses entre a Assistência Medieval e a Intensificação dos Cuidados Médicos no Período 
demonstrando continuidade sobretudo no que se refere ao carácter religioso, que permaneceu fundamental no seio da vida hospitalar, continuando as preocupações com a alma a ser o princípio-guia da assistência aos pobres ${ }^{7}$.

O nosso estudo centra-se no Hospital das Caldas da Rainha, conhecido por Hospital de Nossa Senhora do Pópulo. Este, também de fundação régia (ou, se quisermos, fundado por alguém da família próxima do rei), surgira de raiz pela vontade e acção de D. Leonor no ano de 1485 , sendo que a sua singularidade recaía no facto de ser um hospital sazonal dedicado às curas termais, situado numa zona eminentemente rural. Centrar-nos-emos no universo dos consumos alimentares analisados através dos Livros de Receita e Despesa do Hospital de Nossa Senhora do Pópulo das Caldas da Rainha, com a finalidade de compreender a logística de uma estrutura assistencial rural no primeiro quartel de Quinhentos. A escolha deste hospital assenta em critérios específicos que se prendem não só com a dimensão e natureza da instituição em causa, como também pela presença recorrente, entre 1518 e 1525 , de personagens pertencentes à Casa Real que, por motivos que mais à frente destrinçaremos, beneficiaram de géneros alimentares a suas expensas. $\mathrm{O}$ enfoque dos consumos alimentares em vida de D. Leonor, com particular ênfase nos anos compreendidos entre 1518 a 1525 , será feito através de uma análise qualitativa, pretendendo prospectar os problemas de abastecimento da cozinha daquele hospital, analisar e estabelecer a correlação entre regimes alimentares e estatuto social, entender os itinerários dos produtos, e, ainda que de forma preliminar, abordar o peso da alimentação no contexto global das despesas totais da instituição.

\section{PRIMÓRDIOS DO HOSPITAL E SUA ESTRUTURAÇÃO}

Sobre a fundação do Hospital das Caldas da Rainha vacilam mitos e lendas dos quais é impossível retirar a verdadeira razão que levou D. Leonor a mandar construir a instituição ${ }^{8}$. No entanto, os investigadores actuais, sublinham a acção conjunta de vários motivos: políticos (a afirmação do poder régio), económicos

Moderno». Congresso Comemorativo do V Centenário do Hospital do Espírito Santo, Évora, 1996, pp. 87-103.

${ }^{7}$ Ver Ivo Carneiro de Sousa, A Rainha D. Leonor (1458-1525): Poder, Misericórdia e Espiritualidade no Portugal do Renascimento, Lisboa, Gulbenkian, 2002, pp. 301-307; Nicholas Orme, Margaret Webster, The English Hospital (1070-1570), New Haven and London, Yale University Press, 1995, p. 121. Maria de Lurdes Pereira Rosa, ob. cit., pp. 168 e 169; John Henderson, ob. cit., p. xxxi.

${ }^{8}$ Sobre os diferentes mitos fundacionais veja-se Frei Jorge de São Paulo, $O$ Hospital das Caldas da Rainha até ao ano de 1656, vol. I, Lisboa, Academia das Ciências de Lisboa, 1967; Saúl António Gomes, As Cidades têm uma História: Caldas da Rainha das Origens ao Século XVIII, Caldas da Rainha, PH - Estudos e Documentos, 1994, pp. 21-23. 
(desenvolvimento de uma vila que deveria actuar como «região tampão», evitando o avanço dos coutos do Mosteiro de Alcobaça) e de ordem espiritual ${ }^{9}$.

Mandado edificar em 1485, três anos depois o Hospital de Nossa Senhora do Pópulo funcionava já de forma provisória «pera os pobres doentes receberem graça em suas almas e saúde em seus corpos» ${ }^{10}$. A instituição hospitalar existiu antes mesmo de a região dos banhos ser dotada com o título de «vila», facto que só aconteceria oficialmente a 21 de Março 1511 por mão de D. Manuel $\mathrm{I}^{11}$. Desde a fundação do Hospital de Nossa Senhora do Pópulo os monarcas nomearam membros das suas Casas para os cargos de provedor, almoxarife, escrivão ou vigário $^{12}$.

Embora o Compromisso do Hospital das Caldas da Rainha tenha sido ratificado pelo rei em 1512, estabelecendo os princípios básicos do seu funcionamento, supomos que vigorasse antes da sua confirmação. Determinava a existência de 100 camas, 60 das quais destinadas a homens e mulheres doentes (cada qual dotada de seu enxergão de palha, almadraque de lã, colchão de linho, cabeçal de pena, almofada e meia dúzia de lençóis de linho), 20 «camas de roupa» para peregrinos, servidores e escravos do hospital e as restantes 20 para religiosos e pessoas de estatuto mais elevado, cujas peças de cama seriam «mays delgadas e asy toda a outra roupa milhor» ${ }^{13}$.

O Compromisso confirma que o hospital deveria ser sazonal, abrindo as suas portas no primeiro dia de Abril e fechando-as no derradeiro de Setembro

${ }^{9}$ Ver Nicolau Borges, O Hospital Termal das Caldas da Rainha: Arte e Património, 2 vols., Tese de Mestrado, Lisboa, Universidade de Lisboa, 1998, pp. 5-6; Sandra Cristina Martins de Sousa Gil, Memórias de D. Leonor nas Caldas da Rainha, Tese de Doutoramento, Lisboa, Universidade de Lisboa, 2008, pp. 135-137.

${ }^{10}$ Frei Jorge de São Paulo, ob. cit., p. 91.

${ }^{11}$ Ainda que as Caldas tenham adquirido o estatuto de vila a partir de 1511, a documentação da época utiliza o vocábulo antes dessa data. Veja-se Arquito Distrital de Braga, Fundo Monástico-Conventual (Congregação dos Lóios) - Epílogo e Compêndio da Origem da Congregação de São João Evangelista e do nascimento, vida e morte dos seus três fundadores, pelo Padre Jorge de São Paulo (1658), Ms. 924, fl. 249 onde o frade de hábito azul refere a elevação das Caldas a vila no ano de 1499: «e por causa deste dote sucedeu o motivo santo e a ocasião da fundação do hospital no seu termo que pelos anos de 1499 foi constituído em vila por El-rei Dom Manuel à petição da rainha sua irmã chamada vila das Caldas da Rainha». José Custódio Vieira da Silva, A Igreja de Nossa Senhora do Pópulo das Caldas da Rainha, Caldas da Rainha, V Centenário do Hospital Termal das Caldas da Rainha (1485-1985), 1985, p. 26.

${ }^{12}$ Tenha-se como exemplo os casos de Álvaro Dias Borges provedor do hospital (escudeiro do Infante D. Fernando, pai de D. Leonor), Gomes da Fonseca segundo provedor da instituição (cavaleiro de D. Manuel), Jerónimo Aires provedor (capelão e pregador de D. Leonor), João de Coja e Vasco do Couto respectivamente almoxarife e escrivão (escudeiros de D. João II), João Vieira, vigário da Igreja de Nossa Senhora do Pópulo anexa ao hospital (capelão de D. João II), Bernardo de Castanheda vigário da mesma Igreja (capelão de D. João III), entre outros.

${ }^{13}$ Ver Fernando da Silva Correia, Compromisso do Hospital das Caldas dado pela Rainha D. Leonor sua Fundadora em 1512, Coimbra, Imprensa da Universidade, 1930, p. 15. 
«por serem seis mezes de mayor conveniência e favor com seus calores a cura dos enfermos pobres ordinariamente mal enroupados» ${ }^{14}$. No entanto, os Livros de Contas demonstram que o hospital abria as suas portas dias depois da data estabelecida pelo Compromisso ${ }^{15}$. Outro ponto bastante explícito no Compromisso dizia respeito à separação de sexos, uma vez que se estabelecia a proibição da entrada do sexo masculino nas enfermarias das mulheres, tal como se praticava nos restantes hospitais europeus ${ }^{16}$. A única excepção seria constituída pelas duas visitas diárias feitas pelo provedor na companhia das pessoas por ele autorizadas ${ }^{17}$.

O doente, homem ou mulher, depois de admitido, confessava, comungava, e tomava um banho, após o qual recebia uma camisa lavada, um saio, carapuça, pantufos e um manto, sendo depois conduzido à sua cama ${ }^{18}$. À saída dava-se-lhe uma pequena esmola (em dinheiro, géneros ou ambos) para sustento da viagem de regresso a casa.

As vida das Caldas cedo se assumiu como peça importante no conjunto de senhorios que D. Leonor detinha na Estremadura. Prova disso foram as constantes acções que desenvolveu e que revelam não só a intenção de povoar mais densamente a região como também de lhe atribuir autonomia económica e administrativa face às regiões de Óbidos e Alcobaça ${ }^{19}$.

Em muito contribuiu o hospital mandado edificar por D. Leonor para o processo de diferenciação da vila das Caldas enquanto centro rural relativamente autónomo face aos restantes senhorios que a rainha possuía na Estremadura, mais não seja pela dinâmica que accionava, fazendo gravitar à sua volta muitos aspectos da vida quotidiana da população. Assim, o jogo de forças económicas, políticas e de cariz assistencial que se estabeleceu em torno do Hospital de Nossa

${ }^{14}$ Frei Jorge de São Paulo refere que nos primeiros anos o hospital, abrindo sempre depois da data estabelecida pelo Compromisso, recebia poucos enfermos, apesar do número de camas disponíveis: em 1520 abriu no mês de Maio com dois enfermos, em 1522 com nove, em 1523 com vinte e no ano seguinte apenas com cinco enfermos (ob. cit., vol. II, 1968, pp. 7-8, 450-453).

${ }^{15}$ Ibidem, p. 10.

${ }^{16}$ Ver Mercedes Ínsua Cabanas, «Arquitectura Hospitalaria en Galicia». O Hospital Real de Santiago de Compostela e a Hospitalidade no Camiño de Peregrinación, Galicia, Xunta de Galicia, 2004, pp. 57-85; e Eunice D. Howe, «The Architecture of Institutionalism: Women's Space in Renaissance Hospitals», in Helen Hills (ed.), Architecture and the Politics of Gender in Early Modern Europe, Aldershot, Ashgate, 2003, pp. 63-75.

${ }^{17}$ Frei Jorge de São Paulo, ob. cit., vol. I, pp. 178 e 465.

${ }^{18}$ Fernando da Silva Correia, ob. cit., p. 39.

${ }^{19}$ Vejam-se os 21 traslados de cartas de privilégio, provisões e alvarás em Arquivo Histórico do Hospital Termal das Caldas da Rainha (doravante AHHTCR), Tombo do Hospital de Caldas da Rainha, 1587, [pasta 43], Inv. 298; e ainda Ivo Carneiro de Sousa, «Introdução ao Estudo do Património da Casa e Corte de D. Leonor». Revista da Faculdade de Letras - Línguas e Literaturas, Anexo V - Espiritualidade e Corte em Portugal, Séculos XVI-XVIII, Porto, 1993, p. 32, e, do mesmo autor, A Rainha D. Leonor..., p. 316. 
Senhora do Pópulo contribuiu para o rápido desenvolvimento daquele que seria um dos lugares de eleição de D. Leonor ${ }^{20}$. Mais importante ainda se apresenta quando pensamos no relacionamento favorável que a instituição criou com os habitantes daquelas terras que, inevitavelmente, possuíam relações fortes com o hospital. A criação de arrendamentos com a instituição, as doações feitas pela população, e os privilégios concedidos pelos monarcas, para além das práticas de culto possibilitadas pela igreja do hospital, fizeram com que os habitantes das Caldas se ligassem ao Hospital de Nossa Senhora do Pópulo, e se estabelecesse uma rede de interesses mútuos entre o poder local e a Coroa ${ }^{21}$.

Não obstante, a vila quinhentista onde estava inserido o Hospital de Nossa Senhora do Pópulo mais não era do que um espaço rural, com os habituais campos e pastos ${ }^{22}$. A corroborar este cenário encontram-se os Livros de Receita e Despesa que listam os consumos diários, proveniências de géneros, centros de abastecimento, permitindo não só conhecer as propriedades tuteladas pelo hospital como também a reconstituição da paisagem rural.

\section{OS LIVROS DE RECEITA E DESPESA}

As fontes de rendimento do Hospital Termal das Caldas da Rainha eram constituídas por géneros e rendas em numerário provenientes do património fundiário da instituição, pelas concessões financeiras da Coroa e pelos legados pios que a população e os enfermos remetiam ao hospital ${ }^{23}$. As receitas variavam naturalmente de ano para ano; as despesas, por seu lado, estavam dependentes de um conjunto de condicionalismos que extravasava a vontade dos provedores. Entre outras contingências, podemos referir o número de doentes, as exigências e gravidade das enfermidades, os maus anos agrícolas, a necessidade de obras, ou até a presença de algum membro das elites que obrigava a despesas suplementares.

A minúcia dos registos possibilita a observação do universo dos bens de consumo desta instituição, permitindo vislumbrar as condições e estratagemas de gestão praticados. Desta forma, permitem-nos conhecer não só as condições eco-

${ }^{20}$ Ivo Carneiro de Sousa, A Rainha D. Leonor ..., pp. 182-195.

${ }^{21}$ Os Livros de Notas apresentam-se como uma fonte valiosa para o estudo das relações do Hospital com a população e com a Coroa. AHHTCR, Arrematações, Arrendamentos e Contratos, Livros de Notas, 1525-1607, [pastas 24-28], Inv. 273-277.

${ }^{22}$ Saúl António Gomes, ob. cit., pp. 14, 31-43.

${ }^{23} \mathrm{O}$ mesmo se passa com outros hospitais europeus. Ver Carol K. Manzione, ob. cit., pp. 8295. Para a França do século XVII ver Tim McHugh, ob. cit., pp. 74-81 (Hôpital Général) e pp. 101109 (Hôtel Dieu). 
nómicas de uma instituição hospitalar do século XVI, como também as relações estabelecidas entre os indivíduos e as hierarquias sociais em jogo.

Nos Compromissos dos hospitais da Idade Moderna para além da regulamentação dos direitos e deveres dos profissionais responsáveis por cada uma das secções hospitalares (enfermaria, cozinha, botica, tesouraria, notariado, etc.), há também espaço dedicado aos procedimentos a cumprir quando era chegada a hora de alimentar os doentes ${ }^{24}$.

Os registos das receitas e despesas eram feitos de forma escrupulosa, arrolando a porção do bem comprado, o seu preço por unidade, o número de pessoas por quem seria distribuído e, no final, o valor total pago. Ainda que fosse o provedor a mandar «receber e arrecadar» os bens necessários, o almoxarife ficava responsável pelas compras ${ }^{25}$. Este era acompanhado por um escrivão que devia estar presente no jantar e ceia dos doentes para fazer as porções e ver o que se gastava com eles; registava estes consumos, e dava conta ao provedor das quantidades $\operatorname{gastas}^{26}$.

Os consumos alimentares eram definidos nas duas visitas diárias que o provedor realizava às enfermarias, na companhia de cinco oficiais (escrivão, médico, enfermeiro-mor, cirurgião e boticário), anotando então o escrivão todos os géneros necessários naquele dia ${ }^{27}$. A primeira visita ocorria quando, pelas seis da manhã, o «enfermeiro de baixo» tangia a campainha da Copa, onde o provedor se reunia com os seus acompanhantes. Iam em seguida visitar os enfermos nas enfermarias, e o médico definia um por um o que cada doente comeria na próxima refeição. Terminada a visita da manhã, o escrivão recolhia-se à Casa dos Contos para fazer de novo a lista dos alimentos necessários para que a despesa pudesse ser lançada nos livros ${ }^{28}$. A segunda visita realizava-se por volta das três horas da tarde, e era feita nos mesmos moldes da da manhã. Deste modo, as compras a realizar pelo almoxarife eram ditadas pela visita da manhã, que definia a ceia desse dia, e pela da tarde, que estabelecia o que era necessário para o jantar do dia seguinte.

Os registos efectuados nos Livros de Receita e Despesa podem ser divididos em duas categorias: a primeira diz respeito às despesas diárias regulares

${ }^{24}$ Ver Katharine Park e John Henderson, ob. cit., pp. 183-184; José Pedro Paiva, ob. cit., p. 98; Frei Jorge de São Paulo, ob. cit., vol. II, pp. 476-477.

${ }^{25}$ Sobre as obrigações do almoxarife no tempo de cura e «nos sette meses do Inverno» vejase Frei Jorge de São Paulo, ob. cit., vol. II, pp. 353-355.

${ }^{26}$ Fernando da Silva Correia, ob. cit., p. 29.

${ }^{27}$ Frei Jorge de São Paulo, ob. cit., pp. 432-433 onde o frade relata o ritual e o percurso feito por cada enfermaria aquando das visitas diárias: personagens, objectos, posições assumidas por cada um dos oficiais hospitalares, itinerários percorridos dentro do próprio hospital e um exemplar da tábua onde o escrivão anotava a ração diária, número de banhos, xaropes e purgas respeitantes a cada enfermo.

${ }^{28}$ Idem, vol. II, pp. 38-39. 
(vinho, carne, pão, galinha/frango, azeite), e a segunda compreende as despesas «miúdas», em que se engloba um conjunto muito variado de alimentos, iguarias, especiarias e bens não alimentares. Ainda que o aumento das despesas pudesse estar na relação directa com o número de doentes, os indícios de que dispomos não apontam para uma redução das quantidades de comida por enfermo quando havia mais gente no hospital. Em contrapartida, a presença de membros da família real e seus séquitos tinha incidência directa nas despesas, uma vez que lhes eram proporcionadas as melhores iguarias. No entanto, ainda que o grosso das receitas e das despesas registadas nos livros se relacione com géneros alimentares, a verdade é que nem todos se destinavam à cozinha e, muito menos, à alimentação dos doentes. Por exemplo, a cevada podia servir para tisanas, águas cozidas, pão de segunda qualidade, e também para alimentar bestas e aves. Podia também ser dada como esmola a padres ou transeuntes ${ }^{29}$. O mesmo se passava com outros produtos, como o trigo, azeite ou o mel.

Concentraremos a nossa atenção nos consumos que, partindo da cozinha, se destinavam à alimentação dos doentes, pessoal interno e às despesas alimentares feitas com passageiros e visitantes (clérigos e indivíduos pertencentes aos círculos próximos da Casa Real), excluindo da análise os produtos de botica, esmolas e alimentação do gado e aves.

Nem sempre é fácil distinguir entre «cozinha» e «botica». A linha que demarcava estes dois espaços hospitalares é ambígua, uma vez que, como sabemos, a alimentação constituía uma parte importante das curas dos enfermos ${ }^{30}$. Grande parte das compras de «cousas meudas» era entregue ao hospitaleiro e entre elas podemos sublinhar os «adubos», mel, azeite, frutos secos, entre outros produtos que flutuavam, consoante as necessidades, entre a cozinha e a botica ${ }^{31}$.

\section{OS CONSUMOS ALIMENTARES}

Nos inícios do século XVI, o universo das pessoas que trabalhava na cozinha do Hospital de Nossa Senhora do Pópulo era quase exclusivamente feminino, facto que contrasta com a generalidade das cozinhas nesta época ${ }^{32}$. Nas Caldas observava-se uma divisão sexual do trabalho: às mulheres a cozinha, enquanto os homens se ocupavam da compra e recolha dos alimentos. Os ali-

${ }^{29} \mathrm{Ib}$., pp. 365-367.

${ }^{30}$ Ver Ana Isabel Buescu, neste volume, sobre a importância da medicina galénica na alimentação.

${ }^{31}$ Veja-se AHHTCR, Livro de Receitas e Despesas, 1520-1521, [pasta 1], Inv. 235, fl. 101, onde o exemplo mencionado é bastante evidente.

${ }^{32}$ Raffaella Sarti refere que a maioria do pessoal das cozinhas renascentistas era do sexo masculino (Casa e Família: Habitar, Comer e Vestir na Europa Moderna, Lisboa, Editorial Estampa, 2001, pp. 264-274). Veja-se ainda John Henderson, ob. cit., pp. 200-206. 
mentos confeccionados na cozinha pelas mulheres, depois de prontos, eram levados para a sala da copa onde os servidores repartiam as rações destinadas aos enfermos $^{33}$. Seguia-se a bênção das mesas pelos capelães e o transporte das mesmas rações da sala da copa para as enfermarias pelos respectivos enfermeiros, que as davam aos doentes depois de um ritual de água às mãos ${ }^{34}$.

É bem conhecido o facto de os consumos alimentares, na sua globalidade, constituírem uma das marcas de diferenciação social no período moderno ${ }^{35}$. Para um pobre «comer bem» era sinónimo de quantidade, enquanto para os indivíduos de estatuto elevado significava comer uma variedade tão grande quanto possível de alimentos, sobretudo se raros e valiosos ${ }^{36}$. Muito embora a fonte analisada se apresente bastante concisa no que respeita a quantidades, preços e distribuição quotidiana, não fornece detalhes quanto às rações dadas aos doentes em função da sua enfermidade. Encontramos apenas a prescrição de que os enfermos/as com hidropisia jantavam e ceavam uma galinha ou frango e comiam «pão de calo» ${ }^{37}$. Assim, torna-se impossível definir quais os géneros atribuídos a doentes de febres que deveriam ser diferentes dos ministrados aos que sofriam de gota ou mesmo de «tolhimento da fala e lesão no juízo» ${ }^{38}$. Estes registos ficam igualmente aquém no que toca a informações relativas ao consumo de bebidas por

${ }^{33}$ Esta situação alterou-se no século XVII. A visitação datada de 1634 passa a responsabilizar um homem pela confecção das refeições dos enfermos (Arquivo Distrital de Leiria (doravante ADLRA), Fundo do Real Hospital das Caldas, Foro Jurídico e Visitações, Visitações (1572-1709), Dep.VI-2-C-6, fl. 18).

${ }^{34}$ Ver Fernando da Silva Correia, Origens e Formação das Misericórdias Portuguesas, Lisboa, Henrique Torres, 1944, p. 515; Frei Jorge de São Paulo, ob. cit., vol. II, pp. 37-40.

${ }^{35}$ Ver Maria de los Ángeles Pérez Samper, «Fiesta y Alimentación en la España Moderna: El Banquete como Imagen Festiva de Abundância y Refinamiento». Espacio, Tiempo y Forma, Série IV, História Moderna, t. 10, 1997, p. 54; Fernand Braudel, Civilização Material, Economia e Capitalismo, Séculos XV-XVIII, Volume I: As Estruturas do Quotidiano - O Possível e o Impossível, Lisboa, Teorema, 1992, p. 157; Gianna Pomata, Contracting a Cure: Patients, Healers, and the Law in Early Modern Bologna, Baltimore \& London, The Johns Hopkins University Press, 1998, p. 136.

${ }^{36}$ Maria de los Ángeles Pérez Samper, ob. cit., pp. 55-56.

${ }^{37}$ ADLRA, Fundo do Real..., Livro de Receitas... (1524-1525), Dep. VI-3-B-3, fls. 66v, $320 v, 318$.

${ }^{38}$ O Hospital de Nossa Senhora do Pópulo não admitia enfermos incuráveis como, por exemplo, leprosos e sifilíticos. São vários os registos nos Livros de Contas onde é possível observar a recusa na aceitação de indivíduos portadores dessas enfermidades (AHHTCR, Livro de Receitas e Despesas, 1520-1521, [pasta 1] - Inv. 235, fl. 121v; Frei Jorge de São Paulo, ob. cit., vol. II, p. 35). No entanto, sobre as dietas oferecidas aos leprosos veja-se Carole Rawcliffe, Leprosy in Medieval England, Woodbridge, Boydell Press, 2006, pp. 213-225. Para o caso espanhol veja-se Maria Luisa Zamorano Rodríguez, El Hospital de San Juan Bautista del Toledo durante el Siglo XVI, Toledo, Instituto Provincial de Investigaciones y Estudios Toledanos, 1997, pp. 318-356. 
género. Embora Frei Jorge de São Paulo tivesse afirmado que «rara he a molher a quem se dá vinho», e Fernando da Silva Correia tivesse notado que o número de copos era igual ao de homens que o hospital devia admitir, os Livros de Contas não confirmam esta distinção de forma inequívoca ${ }^{39}$.

Como dissemos, os alimentos eram distribuídos de forma desigual por entre a população do hospital: escravos e servidores, enfermos, peregrinos, frades, profissionais hospitalares, pessoas que gravitavam em torno dos círculos reais e, por fim, os próprios monarcas.

Se lermos os registos, observamos ser recorrente o lançamento em bloco das despesas feitas com os doentes, sem qualquer nota diferencial de sexos, doenças ou idade. O mesmo acontece com os servidores e escravos da Casa, cujos consumos alimentares são arrolados em conjunto, à excepção do assento da liquidação dos seus ordenados e da distribuição das «padas de trigo» que é feita, em alguns anos, com a discriminação dos seus nomes. Já a presença de membros do clero no hospital denota uma maior diferenciação, uma vez que o registo da despesa é sempre efectuado com a menção da ordem a que pertencem. Em regra, a este grupo era dado «pão, vinho ${ }^{40}$, pescado e fruta», sendo bastante frequente a presença no hospital de padres da Congregação de São João Evangelista, mesmo antes da administração da instituição estar na sua posse a partir de 1532-1533. No que concerne aos religiosos mendicantes, os Livros de Contas mostram-nos o hábito de lhes dar dois arráteis de carneiro, duas padas de pão e uma canada de vinho. De resto, o Compromisso estipulava que os frades menores, sobretudo os da observância de São Francisco, deviam ser acolhidos no hospital, independentemente de se encontrarem sãos ou doentes.

O tratamento discriminado segundo o estatuto social atinge o seu máximo no caso da rainha e dos membros da sua Casa, ou outros personagens de Corte. Referimo-nos aos criados mais próximos de D. Leonor que se deslocavam ao hospital, ao serviço da rainha ou para se curarem. Mas a rainha, o seu irmão e os infantes eram sem dúvida objecto do melhor tratamento, e servidos com as melhores iguarias.

${ }^{39}$ Frei Jorge de São Paulo, ob. cit., vol. II, p. 372; Fernando da Silva Correia, Origens e Formação..., p. 515. No que se refere aos suportes de bebida vários são os registos que se prendem com a compra de «copos» e/ou «púcaros», sem especificar a sua utilização. Só pontualmente há a indicação de «púcaros de xaropes para os enfermos», «copos de pau para os enfermos», «copinhos de vidro para xaropes e águas», «copos de pau para os enfermos beberem o vinho»e «púcaros de málega para serviço dos padres provedor e almoxarife». AHHTCR, Livro de Receitas e Despesas, 1520-1521, [pasta 1], Inv. 235, fl. 130; ADLRA, Fundo do Real..., Livro de Receitas... (1523-1524), Dep. VI-3-B-2, fl. 115; Livro de Receitas... (1524-1525), Dep. VI-3-B-3, fls. 322v, $324 \mathrm{v}, 326 \mathrm{v}, 335$.

${ }^{40}$ Veja-se Fernando da Silva Correia, Compromisso do Hospital..., pp. 40-41; Frei Jorge de São Paulo, ob. cit., vol. II, p. 56. 
Começando pelos escalões inferiores, os consumos alimentares dos servidores e escravos do Hospital de Nossa Senhora do Pópulo incidem sobre a compra de carne de vaca e peixe às sextas e sábados de acordo com os preceitos religiosos comuns a todo o hospital. A isto acrescentam-se padas de trigo e, pontualmente, vinho dos enfermos «por ser vinagre» ${ }^{41}$.

Depois dos escravos e servidores vinham os enfermos que seriam, numa lógica actual, os principais destinatários dos recursos do hospital. A alimentação de cada doente era ditada pelo médico do hospital durante as duas visitas diárias que fazia a cada uma das enfermarias. Como sabemos, as dietas alimentares assumiam-se como um dos principais remédios para sanar as enfermidades. Tal como afirma G. Pomata, enquanto as drogas e as acções cirúrgicas se apresentavam como remédios locais, tratando partes específicas do corpo, a alimentação seria 0 «tratamento universal», e portanto a pedra angular de todas as terapias ${ }^{42}$.

$\mathrm{O}$ ingresso de um doente no hospital, para além do exame médico e comunhão prévios, incluía a oferta de uma refeição de pão, carne e vinho; mais tarde, durante a administração lóia, a ceia do dia de ingresso englobava «uma pada de pão e um cacho de passas ou um ovo para cear ${ }^{43}$. Em regra, nos inícios do século XVI um doente fazia duas refeições ao dia: o jantar e a ceia. A primeira refeição, o jantar, que ocorria entre as dez e as onze horas da manhã, era aquela onde a porção da ração era maior e mais nutritiva; por sua vez a ceia, que decorria entre as seis e as sete da tarde, era mais frugal. Cada doente recebia na respectiva enfermaria um arrátel de carneiro ao jantar e meio arrátel da mesma carne à ceia, galinha, frango, caldos e padas de trigo ${ }^{44}$. Para além das refeições principais havia também o almoço e a merenda, destinadas aos doentes mais fracos, constituídas por ovos, conservas e vinho ${ }^{45}$. A estes últimos o Compromisso destinava uma colher de confeitos, «uma talhada de marmelada» ou ovos ${ }^{46}$. O hospital fornecia também ovos às sextas-feiras, substituídos em tempos de escassez por um cacho de uvas passas ${ }^{47}$. À marmelada e aos confeitos era geralmente dado o nome de «mimos para os doentes» ou «doces», sendo que esta última designação

${ }^{41}$ ADLRA, Fundo do Real..., Livro de Receitas... (1523-1524), Dep. VI-3-B-2, fl. 55v.

${ }^{42}$ Gianna Pomata, ob. cit., p. 60. Sobre as relações entre alimentação e medicina veja-se Nancy G. Siraisi, Medieval and Early Renaissance Medicine. An Introduction to Knowledge and Practice, Chicago\&London, The University of Chicago Press, 1990, pp. 120-123.

${ }^{43}$ Frei Jorge São Paulo, ob. cit., vol. II, p. 473.

${ }^{44} \mathrm{O}$ carneiro e as galinhas eram contados às quartas e despendidos na mesma conta com cada enfermo. No que concerne ao carneiro seriam dadas a cada doente ao jantar 459 gramas e à ceia aproximadamente 230 gramas (Frei Jorge de São Paulo, ob. cit., vol. II, p. 475). No caso da despesa dos frangos a distribuição era mais fácil e, segundo Jorge de São Paulo, «não há embaraços na conta», uma vez que por cada duas pessoas se gastava, geralmente, um frango por refeição.

${ }^{45}$ AHHTCR, Livro de Receitas e Despesas, 1520-1521, [pasta 1], Inv. 235, fl. 2; ADLRA, Fundo do Real..., Livro de Receitas... (1518-1519), Dep. VI-3-B-1, fl. 192.

${ }^{46}$ Frei Jorge de São Paulo, ob. cit., vol. II, pp. 41-42.

${ }^{47}$ Ibidem, p. 378. 
englobava não só a marmelada, como também «marmelada de sumos», açúcar rosado e «abóbora cuberta».

Através da fonte conseguimos perceber os circuitos não só dos bens, como, no caso da marmelada, os trajectos e as proveniências do açúcar e marmelos. Pelo Livro de Receitas e Despesas de 1518-1519 conseguimos compreender que a marmelada e o doce não eram produzidos no interior do hospital. Em Setembro de 1519, o hospital pagava a Fernão Vaz, um almocreve, para ir a Alcobaça buscar uma carga de marmelos «para a Rainha Nossa Senhora». No item seguinte do mesmo fólio somos confrontados com o pagamento que João de Coja, à época almoxarife do hospital, fez a Diogo Dias e ao supradito Fernão Vaz, ambos almocreves, por levarem à rainha, então em Vila Franca de Xira, três cargas de marmelos juntamente com as 20 arrobas de açúcar para seguirem pelo Tejo até Xabregas.

A «matéria-prima» usada na confecção da marmelada destinada aos doentes provinha de lugares e fontes distintos. Isto é, enquanto os marmelos eram comprados pelo próprio hospital, o açúcar provinha das doações anuais feitas por D. Manuel I. No entanto, o fabrico da marmelada era levado a cabo pelas religiosas do convento da Madre de Deus e daí a justificação para o açúcar e os marmelos viajarem do Hospital de Nossa Senhora do Pópulo para Xabregas e, depois de transformados em marmelada retornarem ao hospital. Frei Jorge de São Paulo refere «porem a Rainha não faltava com suas correspondências porquanto no convento e no seu paço se faziam as marmeladas, conservas, açúcar rosado e confeitado que a Rainha mandava todos os anos enquanto viveu aos pobres enfermos do seu hospital» ${ }^{48}$.

Este autor refere ainda que no ano de 1524, João de Coja despendeu com os companheiros do provincial de São Francisco 8 reis na compra de «figos passados», em substituição da marmelada, o que revela a sua importância na recuperação dos doentes, devendo, portanto, ser poupada ${ }^{49}$.

Sem distinção, todos os indivíduos do hospital recebiam refeições à base de peixe nos dias santos, quase sempre acompanhado por arroz de leite e, no final, maçã assada ou bredos [planta com a qual se fazia uma espécie de esparregado] ${ }^{50}$. Entre os tipos de peixe consumidos refiram-se os galhudos, as lixas, os litães e as azevias. No entanto, os impedimentos religiosos podiam ser levanta-

${ }^{48} I b .$, vol. I, p. 209.

${ }^{49}$ ADLRA, Fundo do Real..., Livro de Receitas... (1524-1525), Dep. VI-3-B-3, fl. 310: Item sexta feira xxbiii dias do mês [de Outubro] se gastou com ho provincial he cinco frades que com ele vinham de pam xxbiii reis e de pescado xxiiii e de vinho xxiiii e de figos passados oito reis que sam por todos oitenta e quatro reis entregue Álvaro Afonso - lxxxiiii reis [Do lado esquerdo e a letra diferente: bem se mostra que nam gastavam doces com hospedes e tam grave como era um provincial de São Francisco pois lhe davam figos passados por doces].

${ }^{50}$ Ibidem, fl. $275 \mathrm{v}$. 
dos em função do estado dos doentes: os mais debilitados recebiam rações de carne e o provedor ordenava que, em vez das habituais padas de trigo, fossem confeccionados bolos de manteiga especialmente para eles. O mesmo provedor substituía o habitual arrátel e meio de carneiro, por meia perdiz ${ }^{51}$. Note-se também que este podia eventualmente satisfazer as vontades expressas dos doentes. Entre estas, a título de curiosidade, refiram-se a entrida [papas], cabrito, «pão da padeira mimoso», ervilhas e toucinho ${ }^{52}$.

Os doentes em período de purga (6 dias) eram alimentados de forma especial: frango e/ou galinha, cabrito, açúcar rosado, ameixas à ceia antes do início da purga (para estimular o processo purgativo) e um quarto de galinha cozida ao jantar, juntamente com uma colher de confeitos. No próprio dia da purga, comiam mais um quarto de galinha à ceia, agora assada, e na manhã seguinte um limão ao tomá-la novamente ${ }^{53}$.

No período de seis meses em que se abria o hospital, o calendário registava algumas festas religiosas: dia da Ascensão (15 de Agosto), Natal (25 de Dezembro), São João Baptista (24 de Junho), bem como as festas móveis do ciclo da Páscoa (Quinta-Feira Maior, o Sexta-Feira Santa, e Espírito Santo, ). O dia de Nossa Senhora do Pópulo (15 de Agosto), orago do hospital, é indubitavelmente o que a fonte melhor documenta. Todos recebiam rações alimentares melhores e em maior quantidade do que nos dias correntes. Os religiosos recebiam um quarto de galinha assada e um frango ensopado, arroz de carneiro ou de leite, enquanto que os doentes que já frequentavam os banhos recebiam o mesmo arroz de carneiro e um bolo de manteiga ${ }^{54}$.

A fonte não nos proporciona informação sobre a confecção dos alimentos, nem refere os acompanhamentos da carne ou peixe. Outros géneros aparecem sub-registados, como as hortaliças, vegetais e fruta que quase nunca são referenciados, uma vez que o hospital tinha horta e pomar próprios ${ }^{55}$. O mesmo acontece com o registo de aves, dado que o hospital tinha um galinheiro e um pombal, mandados construir por D. Leonor ${ }^{56}$.

${ }^{51}$ Sobre o peixe veja-se Fernand Braudel, ob. cit., vol. I, p. 182.

${ }^{52}$ Veja-se Rafael Bluteau, Vocabulário Português e Latino..., vol. III, Coimbra, Colégio das Artes da Companhia de Jesus, 1712-1728, p. 157 no que se refere ao vocábulo «entrida»: «papas feitas com migalhas de pão metidas em água ou em qualquer outro licor [...]». ADLRA, Fundo do Real..., Livro de Receitas... (1523-1524), Dep. VI-3-B-2, fl. 113v.

${ }^{53}$ Frei Jorge de São Paulo, ob. cit., vol. II, pp. 376 e 474; AHHTCR, Livro de Receitas e Despesas, 1520-1521, [pasta 1], Inv. 235, fl. 14v.

${ }^{54}$ Frei Jorge de São Paulo, ob. cit., vol. II, pp. 380-382.

${ }^{55}$ Ibidem, vol. I, p. 197. No Livro de Receitas e Despesas do ano de 1520-1521 observa-se a fl. 99 o seguinte registo: «Item pagou que comprou por trinta e cinco reis de cebolinho e de alfacinha para dispor na horta a qual deu Álvaro Afonso hortelão - 35 reis». Encontram-se apenas referências a leguminosas na parte relativa às despesas miúdas, onde se anotou a compra de lentilhas ou grão.

${ }^{56}$ Frei Jorge de São Paulo, ob. cit., vol. I, pp. 197 e 199. 
Em suma, os principais géneros resumiam-se a carneiros, galinhas e frangos. Segundo Frei Jorge de São Paulo, o número de carneiros comprados no ano de 1518 (305 carneiros que custaram 32550 reais) foi suficiente para prover o hospital até o ano de $1521^{57}$. No ano seguinte o modo de abastecimento alterouse, deixando de ser compradas as «carneiradas», para se passar a comprar os carneiros no açougue. Álvaro de Coimbra, marchante do hospital, passou a dar todo o carneiro necessário a quatro reis por arrátel, preço que se manteria até ao ano de $1549^{58}$.

A maximização dos recursos destinados aos doentes contrasta com a exuberância da alimentação das pessoas de estatuto social elevado que estanciavam no hospital. Referimo-nos, por exemplo, à presença da rainha D. Leonor que, devido à peste que grassava em Lisboa, se transferiu com o seu séquito para o Hospital de Nossa Senhora do Pópulo em 1518.

Os Livros de Contas dos anos de 1518 e 1525 permitem-nos vislumbrar as dinâmicas que a presença da rainha despoletava: o aumento significativo das despesas, as preocupações relativas ao abastecimento de géneros e, ainda, os circuitos inerentes às estratégias de abastecimento levadas a cabo pelo hospital. A par disto, esta fonte emerge como uma ferramenta fundamental para a reconstituição dos itinerários de D. Leonor no período compreendido entre 1518 e 1525 , já que é possível conhecer os locais onde se encontrava através dos produtos que o hospital lhe enviava.

Não há concordância entre os Livros de Contas e a crónica de Frei Jorge de São Paulo relativamente ao dia em que a rainha chegou ao Hospital, respectivamente 6 e 1 de Novembro. No título das despesas miúdas escrivão e almoxarife assentaram: «Item terça feira dois dias do mês de Novembro deu ho dito Afonso Gonçalvez caçador cento e vinte reais por uma dúzia de pássaros que então foram para a Rainha Nossa Senhora a Aldeia Gavinha a rezão de dez reais cada um deles -120 reais». A corroborar a primeira data, os registos dos gastos feitos à chegada da rainha datam do dia 6 desse mês ${ }^{59}$.

A presença da «fundadora» no Hospital de Nossa Senhora do Pópulo encontra-se documentada quatro vezes nas fontes: Maio de 1501, 1504, Maio de 1507 e, por último, de Novembro de 1518 a Março de $1519^{60}$. Ivo Carneiro de Sousa

${ }^{57}$ Ibidem, vol. II, p. 491.

${ }^{58}$ No ano de 1524-1525 quem levava os presentes à rainha a Alenquer e a Aldeia Gavinha era o marchante do Hospital, Álvaro de Coimbra (ADLRA, Fundo do Real..., Livro de Receitas... (1524-1525), Dep. VI-3-B-3, fls. 321v e 327). Os Livros de Notas, custodiados pelo AHHTCR, são bastante detalhados no que respeita aos contratos estabelecidos com o «carneireiro». Veja-se a título de exemplo: Livro Primeiro de Notas (1525-1540), [pasta 24], Inv. 273, fls. 66-67.

${ }^{59}$ ADLRA, Fundo do Real..., Livro de Receitas... (1518-1519), Dep. VI-3-B-1, fl. 222v.

${ }^{60}$ Relativamente a estas datas veja-se: 24 de Maio de 1501, ADLRA, Fundo do Real..., Avulsos, Dep.VI-Gav.2, doc. 14; em 1504 Ivo Carneiro de Sousa, A Rainha D. Leonor..., p. 187 
refere que a rainha estaria nos paços de Santo Elói em Lisboa desde finais de Dezembro de 1517 e aí teria permanecido até à sua ida para as Caldas ${ }^{61}$. No entanto, antes de se ter fixado no Hospital de Nossa Senhora do Pópulo, D. Leonor esteve algum tempo em Aldeia Gavinha, pois no registo das despesas miúdas do mês de Outubro o escrivão anota todos os «mimos» que o hospital the enviou. Assim, de 12 de Outubro a 2 de Novembro de 1518, o hospital ordenou que fossem capturadas aves (31 pássaros, 1 dúzia de rolas, meia dúzia de perdizes, mais outra dúzia de pássaros), peixes de Salir do Porto e do Arelho (1 dúzia de douradas, 1 dúzia de linguados, 1 carga de ostras, 2 dúzias de pescadas frescas, percebes, 2 dúzias de salmonetes, 4 dúzias de besugos, mais 2 cargas de ostras, 1 marreca do mar, 1 canastra de amêijoas, mais 30 salmonetes, 16 besugos, 6 robalos da costa, 5 linguados, 1 pargo), 14 coelhos e 1 lebre capturados na Serra do Bouro, fruta («canastra de maçãs cheiinhas de Aljubarrota»), 2 onças de açafrão e 1 saco de castanhas ${ }^{62}$. Como vemos, os presentes enviados a D. Leonor com destino a Aldeia Gavinha não incluem carne vermelha. Ainda a registar a referência a $\mathrm{D}$. Manuel, também fugido à peste, que sabemos ter visitado a Rainha em Aldeia Galega, a 18 de Outubro de 1518. Entretanto, D. Leonor pedira a Jerónimo Aires, provedor do hospital, que lhe enviasse as supraditas pescadas e percebes para «agasalhar e banquetear» o irmão ${ }^{63}$.

Os Livros de Contas deixam igualmente transparecer o frenesim que antecedeu a chegada da rainha ao hospital. Partindo do princípio que a rainha chegou sábado, dia 6 de Novembro, como nos diz o Livro de Contas, dois dias antes da sua chegada o hospital recebeu os moços e escravos da guarda roupa da rainha, a quen forneceram pão e peixe por não haver que comer na vila. Não sabemos quantos seriam os indivíduos ao serviço da soberana, mas naquele dia gastaramse 147 reis $^{64}$.

refere a soberana a participar «na procissão do Corpus Christi das Caldas, encomendando mesmo a Gil Vicente a representação, para o acontecimento religioso, do Auto de S. Martinho»; a 11 de Maio 1507: ADLRA, Fundo do Real..., Avulsos, Dep. VI-Gav.3, doc. 25; por último, a estadia de D. Leonor nas Caldas entre o período compreendido entre Novembro de 1518 e Março de 1519 encontra-se referenciada não só na documentação da época (ADLRA, Fundo do Real..., Livro de Receitas... (1518-1519), Dep. VI-3-B-1; IAN/TT, Corpo Cronológico, Parte I, Maço 23, doc. 138) como também na obra do século XVII escrita por Frei Jorge de São Paulo, ob. cit., vol. I, pp. 204208.

${ }^{61}$ Ivo Carneiro de Sousa, A Rainha D. Leonor..., p. 189.

${ }^{62}$ ADLRA, Fundo do Real..., Livro de Receitas... (1518-1519), Dep. VI-3-B-1, fls. 221-223.

${ }^{63}$ Ibidem, fl. 221.

${ }^{64} \mathrm{Ib}$., fl. 223. Ivo Carneiro de Sousa aponta que a rainha levara para as Caldas «cerca de setenta escravos, muitos dos quais passariam a servir no Hospital de Nossa Senhora do Pópulo, em funções subalternas...» (A Rainha D. Leonor..., p. 172). No Livro de Receitas e Despesas daquele ano apenas se encontram referenciados os nomes de alguns servidores da rainha, como Catarina da Rosa e Gonçalo Dias, respectivamente guarda-roupa e barbeiro/sangrador. O boticário, os capelães, as damas e escravos são também referidos, ainda que se omitam os seus 
Outros gastos prepararam com antecedência a chegada da rainha. O provedor, Jerónimo Aires, providenciou a compra de lenha de zimbro recolhida na Serra do Bouro «para se queimar na câmara da Rainha Nossa Senhora que então aqui veio ter fugida da peste»; adquiriu cargas de maçãs de várias qualidades em Aljubarrota das quais algumas acabaram por apodrecer antes da rainha chegar. Da mesma forma, foi preciso melhorar o aspecto dos trabalhadores da Casa que receberam novos vestidos de burel ${ }^{65}$.

A presença da rainha alterou os calendários de funcionamento do hospital que abriu excepcionalmente duas vezes naquele ano, dando lugar a dois períodos de cura, um dos quais obrigando a receber doentes no Inverno. O primeiro ciclo registou-se de 1 de Dezembro de 1518 a 13 de Março de 1519, data em que a rainha partiu para Muge, e o segundo ocorreu de 3 de Maio a 20 de Setembro de 1519. O Livro de Receitas e Despesas daquele ano regista uma série de gastos particulares com os doentes da rainha, isto é, «pessoas que adoeciam dos que vinham com sua Alteza» ${ }^{66}$. Logo no dia da sua chegada, o provedor Jerónimo Aires apresentou-lhe à mesa um conjunto de iguarias ${ }^{67}$.

Para além de permitir compreender o tipo de relação que a rainha mantinha com o hospital, a fonte dá-nos a indicação da localização dos aposentos da rainha, «que estão hoje sobre as casas dos contos e refeitório» ${ }^{68}$. «Casas» essas que o provedor mandou juncar e pincelar como atestam as referências à compra de um pincel e a carradas de junco ${ }^{69}$. Acrescenta, todavia, Frei Jorge que «sendo tão grandiosa e liberal [a rainha] recebia presentes das rendas dos pobres que ela mesma lhas tinha compradas e concedidas, como dando a entender se dava por contentíssima porem-se em sua mesa iguarias à custa do seu hospital e do cabedal da mesma pobreza» ${ }^{70}$. A análise dos Livros de Contas leva-nos a perguntar se as despesas do hospital durante toda a estadia da rainha, de 6 de Novembro de 1518 a 13 de Março de 1519, se resumiram aos três dias documentados na fonte (6, 8 e 26 de Novembro de 1518). É provável que digam respeito apenas aos banquetes de boas-vindas oferecidos à rainha e ao seu séquito, e que posteriormente as despesas tenham corrido por conta da própria D. Leonor.

nomes. Os servidores da rainha, embora ocasionassem despesas, também auxiliavam nas tarefas do hospital: o barbeiro da rainha cortava as barbas e cabelos aos enfermos, os seus capelães rezavam as vésperas de São Silvestre e o boticário supria a falta de azinhavre na botica do hospital. Veja-se ADLRA, Fundo do Real..., Livro de Receitas... (1518-1519), Dep. VI-3-B-1, fls. 242v, $249,232 \mathrm{v}$.

${ }^{65}$ Ibidem, fls. 220v, 224v e 223.

${ }^{66} \mathrm{Ib}$., fls. 113 e $225 \mathrm{v}$.

${ }^{67}$ Frei Jorge de São Paulo, ob. cit., vol. I, p. 206.

${ }^{68}$ Ibidem, p. 207.

${ }^{69}$ ADLRA, Fundo do Real..., Livro de Receitas... (1518-1519), Dep. VI-3-B-1, fl. 220v.

${ }^{70}$ Frei Jorge de São Paulo, ob. cit., vol. I, p. 206. 
Os gastos exorbitantes com alimentação não gravitavam apenas em torno da figura da rainha. Se é verdade que trouxe «caza e toda a sua recamara para este seu hospital», a sua presença provocou a afluência de pessoas ilustres à vila das Caldas $^{71}$. Entre esses hóspedes, membros da hierarquia superior da Igreja, como é o caso do Provincial da Batalha a 26 de Novembro de 1518 e do Bispo de Coimbra, D. Jorge de Almeida, de 18 de Dezembro de 1518 ao dia de São Tomé de 1519. Ou ainda, homens próximos do rei D. Manuel, como é o caso de Luís Homem. O Livro de Receitas e Despesas refere a figura do capelão do Marquês de Vila Real que, segundo Frei Jorge, fora visitar a rainha. O mesmo acontecendo a 15 de Janeiro com o «padre Jerónimo da Vidigueira, Geral da Congregação de São João Evangelista» que fora de São Bento de Xabregas até ao hospital com dois religiosos visitar a mesma Senhora ${ }^{72}$.

No volume II da sua crónica, Frei Jorge de São Paulo refere que «no ano de 1518 estando a Raynha D. Leonor neste Hospital veio a ele o Senhor D. Pedro sobrinho del-Rey de Manicongo que se doutrinava em o nosso convento de Santo Elói de Lisboa por mandado del Rey D. Manuel» ${ }^{73}$. Não temos testemunhos da presença de D. Pedro em 1518, mas sim durante 1519, concretamente em 29 de Março, data na qual sabemos que falecera e fora enterrado nas Caldas ${ }^{74}$. Conhece-se um outro sobrinho daquele rei, desta vez um tal D. João ${ }^{75}$.

Há que sublinhar que todos os gastos decorrentes destas visitas foram feitos à custa do hospital, sem qualquer patrocínio da rainha. Observando os Livros de Contas, percebemos que o hospital se transformou, devido à sua presença, numa Corte em pequena escala, gravitando em torno de D. Leonor. As despesas com doentes ficam assim relegadas para segundo plano, surgindo apenas esporadicamente. Em suma, o grosso das preocupações durante aqueles meses que mediaram entre Novembro de 1518 e Março de 1519 incidiu de forma sistemática no agasalho da rainha, do seu séquito e dos seus visitantes.

Alguns dos servidores da rainha permaneceram no hospital depois desta ter partido para Muge. Entre os gastos efectuados com eles destaca-se a presença de Catarina da Rosa que, segundo Ivo Carneiro de Sousa, foi uma das mais importantes damas de D. Leonor ${ }^{76}$. Os gastos com Catarina da Rosa são recorrentes e estendem-se aos moços e escravos que a acompanhavam.

${ }^{71}$ Ibidem, p. 204; vol. II, p. 91.

${ }^{72} \mathrm{Ib}$., vol. I, p. 206.

${ }^{73} \mathrm{Ib}$., vol. II, p. 91.

${ }^{74}$ ADLRA, Fundo do Real..., Livro de Receitas... (1518-1519), Dep. VI-3-B-1, fl. 250.

${ }^{75}$ Ibidem, fl. 249v.

${ }^{76}$ Ivo Carneiro de Sousa, A Rainha D. Leonor..., p. 848. No dia 15 de Setembro de 1521 o almoxarife João de Coja pagou a Pêro Anes, carpinteiro, 175 reais por três dias e meio em que andou a forrar a câmara que fizera nos paços da rainha para a dita Catarina da Rosa. Mais gastara na compra de 300 pregos para soalhar a dita câmara 120 reais. AHHTCR, Livro de Receitas e 
Embora D. Leonor já tivesse deixado o hospital a 14 de Março de 1519, o provedor Jerónimo Aires continuou a enviar-lhe «mimos» até à data da sua morte $^{77}$. Nos dias que se seguiram à sua partida observam-se os gastos mais avultados. A lista é significativa: uma carga de ostras, meia dúzia de linguados, duas douradas, um congro, um robalo, um cesto de amêijoas, 30 pescadas, quatro ruivos, meio alqueire de sal, uma carga de marisco, uma golpelha de linguados e robalos e uma carga de pescadas frescas.

Ivo Carneiro de Sousa documenta a rainha em Lisboa nos primeiros meses de 1520, com registos em Março relativos a Xabregas e em Abril a Vila Franca de Xira, mas com regresso a Lisboa no final do Verão ${ }^{78}$. Nos Livros de Receitas e Despesas do hospital só temos novamente referência a D. Leonor a partir de Novembro de 1520, uma vez que não chegou até nós o Livro de Contas de 15191520. Assim, naquele mês e ano D. Leonor enviou ao hospital um seu reposteiro, de nome Gabriel Gomes, para comprar galinhas tendo o hospital feito seguir as ditas galinhas em oito bestas, juntamente com sacos de castanhas e pescadas ${ }^{79}$.

Em Janeiro do ano seguinte o hospital continuou a enviar presentes à rainha que se encontrava em Xabregas. Em Julho e Setembro os presentes consistiam em pipas de vinagre, e em Setembro 1400 maçãs «camoezas» compradas em Aljubarrota, e os habituais marmelos ${ }^{80}$.

Embora não tenha chegado até nós o Livro de Contas de 1522, Frei Jorge de São Paulo refere que nesse ano a rainha ordenou ao provedor que fornecesse todo o peixe necessário aos frades de São Francisco que celebravam o Capítulo Geral no convento de Alenquer. Ou seja, uma lista impressionante de «72 douradas, 249 muges e tainhas, 730 choupas, 51 azevias, em que tudo montou a 1105 peixes e em dinheiro 2860 reis [...] e na semana seguinte de 23 e 24 do mês lhe mandou mais quatro canastras de peixe em duas cargas: levaram 43 douradas e 37 muges e tainhas, 50 choupas, um robalo mui grande, 49 azevias, dois linguados que tudo custou dois mil reis» ${ }^{81}$ !

Se observarmos as Receitas e Despesas de 1523-1524 apercebemo-nos que desde Outubro de 1523 a Setembro de 1524 o hospital enviou presentes todos os meses à Rainha (com excepção de Fevereiro), e houve também correspondência epistolar entre ambos. Em Outubro 1523 a rainha estava doente em Vila Franca

Despesas, 1520-1521, [pasta 1], Inv. 235, fls. 69, 129. Ver também sobre a mesma pessoa, ADLRA, Fundo do Real..., Livro de Receitas... (1518-1519), Dep. VI-3-B-1, fls. 142, 148v, 179v, $184 \mathrm{v}-185,188 \mathrm{v}, 191$ e 213.

${ }^{77}$ Frei Jorge de São Paulo, ob. cit., vol. I, p. 208

${ }^{78}$ Ivo Carneiro de Sousa, A Rainha D. Leonor..., p. 198.

${ }^{79}$ AHHTCR, Livro de Receitas e Despesas, 1520-1521, [pasta 1], Inv. 235, fls. 82, 87, 91-91v.

${ }^{80}$ Ibidem, fls. 95, 113v, 123 e 126v-127.

${ }^{81}$ Frei Jorge de São Paulo, ob. cit., vol. I, pp. 105 e 209. 
de Xira e o hospital enviou-lhe queijadas, porcos, cinco pipas de vinho (três delas de 20 almudes e duas de 26 almudes), empadas, coelhos e 200 marmelos da Batalha e de Óbidos ${ }^{82}$. Nos meses de Outubro e Novembro daquele ano registouse a presença no hospital de criados da rainha como Luís Fernandes, Lopo Gonçalves e João Murzelo (guarda-reposte) que traziam recados seus para o provedor enquanto permanecia em Vila Franca. Ainda no mês de Novembro, o Livro de Contas refere que o provedor enviou 12 perdigões e língua cervina à rainha, então em Xabregas. Em Dezembro foram-lhe enviados para Alhandra 15 almudes de vinagre trazidos do Alentejo e língua cervina que se apanhara na Batalha $^{83}$.

Em Janeiro de 1524, a rainha permanecia em Xabregas. Em Março são-lhe enviados cem reais de peixe, empadas e pombos; em Abril o almoxarife despendia 890 reais com 26 almudes «de vinagre que levaram para as freiras da Madre de Deus», seguidas de mais três pipas em Maio. Em troca a rainha mandou, no mesmo mês de Abril, conservas para o hospital ${ }^{84}$. No mês de Maio seguiam para D. Leonor oito infusas de nata, manteiga crua, uma pipa de vinagre, queijadas, banha de porco e um cântaro de mel ${ }^{85}$. De Junho a Setembro de 1524, o Livro de Contas mostra-nos que a correspondência entre o provedor do hospital e a rainha foi bastante profícua, sendo constantes as missivas que o primeiro enviava para Lisboa juntamente com marmelos, codornos [pêras grandes] e maçãs camoezas para Xabregas ${ }^{86}$. Para além destes presentes mensais, a rainha recebia como hóspede o infante D. Fernando, seu sobrinho, escrevendo logo a Jerónimo Aires para que, desde o hospital, lhe fossem enviados «caça, pescado, marisco, fruta, manteigas, natas, queijadas, galinhas, adens [patos], rolas, capões e uma vitela ${ }^{87}$.

De Maio a Junho de 1525, estando D. Leonor em Alenquer, o hospital enviava-lhe pescado, salmonetes, marisco, linguados, coelhos e láparos. Em Julho, estanciando em Aldeia Gavinha, onde permaneceria até se deslocar para Alhandra no mês seguinte, a rainha recebeu do hospital, cartas do provedor, vitela, pescado e perdigões ${ }^{88}$. Em Agosto e Setembro encontrava-se em Alhandra, de

${ }^{82}$ ADLRA, Fundo do Real..., Livro de Receitas... (1523-1524), Dep. VI-3-B-2, fls. 31v, 32v, $41,68,78 \mathrm{v}-79 \mathrm{v}$.

${ }^{83}$ Ibidem, fls. 82-82v.

${ }^{84} \mathrm{Ib} ., \mathrm{fl} .93$.

${ }^{85} \mathrm{Ib}$., fls. 91, 93-99v.

${ }^{86} \mathrm{Ib}$., fls. 109-121v. Vejam-se as observações feitas por Jorge de São Paulo relativamente ao ano de 1524 quanto «a largueza e meudeza de couzas que a Raynha Dona Leonor mandava sempre de Lisboa pera os pobres», ob. cit., vol. II, p. 362.

${ }^{87}$ ADLRA, Fundo do Real..., Livro de Receitas... (1523-1524), Dep. VI-3-B-2, fl. 83; Frei Jorge de São Paulo, ob. cit., vol. I, pp. 209-210 e vol. II, p. 92.

${ }^{88}$ ADLRA, Fundo do Real..., Livro de Receitas... (1524-1525), Dep. VI-3-B-3, fls. 321v$327 \mathrm{v}$. 
onde partiria para o seu paço em Xabregas, acabando por falecer em Lisboa a 17 de Novembro de 1525. Em Alhandra recebeu 14 pássaros, coelhos, queijadas e tigeladas que se fizeram no dia de Nossa Senhora do Pópulo, marmelos, duas tainhas, salmonetes, besugos ${ }^{89}$.

\section{CONCLUSÕES}

O hospital das Caldas manteve um carácter rural ao longo da primeira metade do século XVI. Era parte integrante dos senhorios da Rainha, e, quando necessário, monopolizava recursos em favor desta e da sua Casa, secundarizando os pobres. Mesmo ausente do hospital, a rainha recebia nas terras onde estanciava, ou em Lisboa, onde tinha o seu paço de São Bartolomeu e o seu convento da Madre de Deus Xabregas, numerosos produtos enviados pelo provedor do hospital. Não obstante o seu carácter senhorial, e as rendas devidas a D. Leonor, as relações desta com o hospital procuraram revestir-se de alguma reciprocidade. A rainha fazia-lhe frequentes doações, não só mediante a confecção de marmelada, confeitos e doces no seu convento de Xabregas mas também em géneros provenientes de outras regiões do país, como passas do Algarve, ameixas secas e figos.

Os Livros de Contas do Hospital de Nossa Senhora do Pópulo permitem-nos seguir os itinerários da rainha mesmo quando enferma; quase sempre incidiam sobre as vilas que detinha na Estremadura. Alenquer, Vila Franca de Xira, Caldas, Aldeia Gavinha e Aldeia Galega da Merceana são, depois de Lisboa e dos paços em Xabregas, os seus percursos habituais ${ }^{90}$. Não se percebe, no entanto, se estes trajectos terão, de alguma forma, implícitas estratégias de abastecimento a que somente vilas pertencentes ao seu património conseguiriam fazer face. Muito possivelmente os traçados de viagem eram previamente estudados e definidos em função dos recursos que aquelas terras podiam proporcionar.

Colmatar as exigências alimentares que a presença de D. Leonor despoletava não era fácil e, sobretudo, ficava caro. Ainda que todas aquelas terras lhe pertencessem, a verdade é que, muitas das vezes, e sobretudo durante os meses de Novembro de 1518 a Março de 1519, os consumos da rainha, do seu séquito e de todos aqueles que a visitaram, se fizeram às custas das rendas do hospital e, consequentemente, dos seus «pobres enfermos».

Mais do que o recurso à medicina e à farmacopeia, a cura dos enfermos consistia numa tríade que se repetia vezes sem conta: cura da alma (serviço religioso), cura do corpo (fundamentalmente através de uma alimentação substancial, da cirurgia e das mezinhas da botica) e, em consonância com as duas primeiras, os banhos termais. Ainda assim, a estratificação social da época é passível de ser

\footnotetext{
${ }^{89}$ Ibidem, fls. $330-334 \mathrm{v}$.

${ }^{90}$ Ivo Carneiro de Sousa, A Rainha D. Leonor ..., pp. 194-195.
} 
observada nas mais simples acções, como é o caso dos consumos alimentares que variavam em quantidade e qualidade consoante o grupo social a que o indivíduo pertencia. $\mathrm{O}$ hospital rural quinhentista não escapava aos preceitos hierárquicos da sociedade da época. A afluência de pessoas insignes ao Hospital de Nossa Senhora do Pópulo fazia com que as despesas rapidamente aumentassem e a instituição se transformasse num local de luxuosa aposentadoria da alta nobreza e do alto clero. 